\title{
Qualidade de fruto e produtividade de pessegueiros submetidos a diferentes épocas de poda
}

\author{
Fruit quality and productivity of peaches submitted to different pruning dates

\begin{abstract}
Michél Aldrighi Gonçalves ${ }^{\mathrm{I}}$ Luciano Picolotto $^{\mathrm{II}}$ Fernanda Quintanilha Azevedo $^{\text {II }}$
\end{abstract}

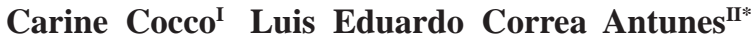

RESUMO

Com o presente trabalho objetivou-se avaliar as características produtivas de diferentes genótipos de pessegueiro (Prunus persica (L.) Batsch.), submetidos a podas em épocas distintas na região de Pelotas-RS. O experimento foi conduzido em uma área experimental pertencente à Embrapa Clima Temperado (CPACT), durante os anos de 2009 e 2010. Os tratamentos foram compostos de combinações de três épocas de poda [poda de inverno $(P I)$, poda de inverno mais poda de verão (PIV) e poda de verão (PV)] e três genótipos [Cascata 805, Cascata 834 (BRS Kampai) e Cascata 952 (BRS Rubimel)], resultando em nove tratamentos distintos. Para as variáveis firmeza de frutos, $\mathrm{pH}$, sólidos solúveis (SS), acidez titulável (AT), relação SS/AT e cor, não foi verificada interação entre os fatores estudados. Os frutos de BRS Kampai apresentaram maior firmeza, assim como a poda apenas no período de verão. O genótipo BRS Kampai apresentou frutos com maior SS e AT dentre os estudados e as plantas de BRS Kampai e BRS Rubimel apresentaram frutos com coloração vermelha mais intensa de epiderme, independentemente da época de poda. Verificou-se que a poda apenas no período de verão induziu à produção de frutos menores. Os genótipos BRS Kampai e BRS Rubimel apresentaram produtividades semelhantes, independente do sistema de poda aplicado. Em geral, as características físico-químicas dos frutos não são alteradas com as variações de época de poda estudadas. No entanto, as variáveis de qualidade física e as relacionadas com a produção sofrem influência direta da época de poda.

Palavras-chave: Prunus persica, genótipos, práticas culturais, fruto de mesa.

\section{ABSTRACT}

The present research aimed to evaluate the productive characteristics of different genotypes of peach (Prunus persica (L.) Batsch.), submitted to pruning at different times in Pelotas / RS. The experiment was conducted in an experimental area that belongs to Embrapa Temperate Climate (CPACT) during 2009 and
2010, the treatments consisted of combinations of three pruning times [winter pruning (PI), winter pruning plus summer pruning $(P I V)$ and summer pruning $(P V)]$ and three genotypes [(Cascata 805, Cascata 834 (BRS Kampai) and Cascata 952 (BRS Rubimel)], resulting in nine different treatments. There was no interaction between factors for the variables fruit firmness, $\mathrm{pH}$, soluble solids (SS), titratable acidity (TA), SS / TA ratio and color. Higher firmness was observed for BRS Kampai fruit and for summer pruning alone. The fruit of genotype BRS Kampai had the highest SS and TA among those studied, the plants of BRS Kampai and BRS Rubimel had fruit with more intense epidermal red coloration, regardless the pruning time. It was found that the pruning only in summer induced the production of small fruits. Genotypes BRS Kampai and BRS Rubimel productivity showed similar system independent pruning applied. Overall, physicochemical characteristics of the fruit do not change with variations in pruning time, although physical characteristics and those related to production suffer direct influence of pruning time.

Key words: Prunus persica, genotypes, cultural practices, fresh fruit.

\section{INTRODUÇÃO}

A produção de pêssego nacional teve um acréscimo nos últimos anos de aproximadamente $9 \%$ ao ano, sendo o principal contribuinte para este quadro o aumento da produção de frutas destinadas ao mercado de fruta fresca, visto que a produção de pêssego destinado à indústria têm se mantido estável (MADAIL \& RASEIRA, 2008). Prova desta tendência de mercado é o aumento da procura por cultivares que produzam frutos de baixa acidez, estes destinados ao consumo in natura (RASEIRA et al., 2010).

IPrograma de Pós-graduação em Agronomia (PPGA), Universidade Federal de Pelotas (UFPel), Pelotas, RS, Brasil.

"Embrapa Clima Temperado, BR 392, Km 78, 96001-970, Pelotas, RS, Brasil. E-mail: luis.antunes@embrapa.br. *Autor para correspondência. 
Na busca da ampliação de opções aos produtores e, assim, atender suas novas necessidades, a Embrapa Clima Temperado, através do "Programa de Melhoramento de Fruteiras de Caroços”, vem, ao longo dos anos, desenvolvendo novas cultivares, acompanhando as constantes transformações e exigências que o mercado impõe. Atendendo a demanda gerada pelos produtores deste segmento, nos anos de 2007 e 2009, foram lançadas as cultivares 'BRS Rubimel' e 'BRS Kampai', respectivamente (SCARANARI et al., 2009). Outras seleções vêm se destacando dentro do programa como possíveis lançamentos, sendo a Cascata 805 um desses destaques. Mesmo com o lançamento de novas cultivares, os produtores de pêssego ainda encontram algumas dificuldades, sendo importante identificar os possíveis gargalos produtivos que não permitem a eles obterem um retorno econômico satisfatório. Um destes, já identificado, refere-se às tecnologias de produção aplicadas, que ainda dependem de métodos mais econômicos de produção, sobretudo os que dizem respeito à poda e condução das plantas, para assim reduzir a mão de obra e, por consequência, o custo de produção (ZANETTI \& BIASI, 2004). Sabe-se que a produção de pêssego é influenciada por muitos fatores, incluindo o clima, localização do pomar e práticas culturais como a poda. BOUND \& SUMMERS (2001) destacaram que as práticas culturais são fatores que podem ser manipulados, podendo apresentar variações de acordo com a cultivar trabalhada. A planta de pessegueiro é sensível a variações na prática da poda, sendo assim, várias pesquisas vêm sendo realizadas tanto no sentido de simplificar ou mecanizar seu cultivo, como também de buscar melhorias na qualidade dos frutos. Uma técnica que vem sendo utilizada em regiões mais quentes é a poda de renovação em plantas de pessegueiro, realizada logo após a colheita, que demonstrou ser um método eficiente para aumentar a área produtiva das plantas, bem como para retardar o desfolhamento e a quebra de dormência natural, evitando o florescimento nos meses de verão (ARAUJO et al., 2008).

Nesse sentido, com o presente trabalho, objetivou-se verificar o comportamento de três genótipos quanto à produção e qualidade de frutos, quando submetidos a diferentes épocas de poda na região de Pelotas, RS.

\section{MATERIAL E MÉTODOS}

O experimento foi realizado no campo experimental da Embrapa Clima Temperado, localizado no município de Pelotas, RS (coordenadas $31^{\circ} 40^{\prime} 41.29$ ” S e $52^{\circ} 26^{\prime} 22.05^{\prime}$ ' W e, altitude de 70m). O clima, segundo a classificação de Köppen, é do tipo “Cfa”, ou seja, é temperado úmido com verões quentes. O solo do local é moderadamente profundo, com textura média no horizonte A e argilosa no B, classificados como Argissolo Vermelho Amarelo (EMBRAPA, 2006).

O pomar utilizado no experimento foi implantado no ano de 2006, com espaçamento de 1,5mx5,0m, conduzido no sistema de ' $\mathrm{Y}$ ' duplo, sendo utilizados como copa os genótipos Cascata 805, Cascata 834 (BRS Kampai) e Cascata 952 (BRS Rubimel), enxertadas sobre porta-enxerto Capdeboscq. Os três genótipos utilizados no trabalho são destinados ao consumo in natura, sendo que a seleção 805 foi obtida através do cruzamento entre Chimarrita e Della Nova e ambas as cultivares 'BRS Kampai' e 'BRS Rubimel', através do cruzamento entre Chimarrita e Flordaprince (SCARANARI et al., 2009).

As podas foram realizadas em duas épocas, uma executada logo após a colheita, nas datas de 15 de dezembro em 2008 e 22 de dezembro em 2009 (poda de verão), e outra no período de inchamento das gemas, sendo esta realizada no dia 7 de agosto, tanto em 2009 como em 2010 (poda de inverno). As plantas que receberam apenas poda de verão foram podadas mais drasticamente, permanecendo apenas os ramos destinados à produção no ano seguinte, já que estas não receberam intervenções no período de inverno. Os tratamentos foram constituídos pela combinação entre os diferentes genótipos e as diferentes épocas de poda [poda de inverno (PI), poda de inverno mais poda de verão (PIV) e poda de verão (PV)].

A prática de raleio dos frutos foi realizada manualmente quando os frutos atingiram diâmetro médio de 2,5cm, utilizando um padrão pré-definido: distância entre frutos de 8 a $10 \mathrm{~cm}$ em ramos vigorosos e de 12 a $15 \mathrm{~cm}$ nos ramos de menor vigor. Frutos de ramos fracos, com diâmetro inferior a $5 \mathrm{~mm}$ no ponto de inserção, foram eliminados. Os demais tratos culturais e tratamentos fitossanitários foram realizados conforme as Normas Técnicas e Específicas da Produção Integrada de Pêssegos (NTEPIP) (FACHINELLO et al., 2003).

Para a qualidade de fruto, as características avaliadas foram firmeza de polpa, utilizandose um penetrômetro manual, com ponteira plana de oito milímetros $(8 \mathrm{~mm})$ de diâmetro, com três repetições de dez frutos cada, frutos estes colhidos das três plantas da parcela (duas leituras por fruto, em lados opostos na região equatorial), expresso 
em quilograma-força (Kgf); sólidos solúveis (SS), determinado com o auxílio de refratômetro digital com compensação automática de temperatura e os resultados mensurados em ${ }^{\circ}$ brix; acidez titulável (AT), obtida através da diluição de $10 \mathrm{~mL}$ de suco em 90mL de água destilada e posterior titulação com solução de hidróxido de sódio $(\mathrm{NaOH})$ 0,1N, até atingir $\mathrm{pH}$ 8,1 (ponto de viragem), e os resultados expressos em porcentagem (\%) de ácido cítrico; relação SS/AT, obtida através do quociente entre as duas variáveis; pH, determinado em pHmetro digital; coloração da epiderme, mensurada pelo sistema registrado pela Commission Internationale de I'Eclairage L*, a* e b* (CIE-Lab) e determinada através do colorímetro eletrônico, Minolta 300, com iluminante D 65 e abertura de $8 \mathrm{~mm}$. Os valores foram expressos em ângulo Hue $\left(h^{\circ}\right)$ pela fórmula $\mathrm{h}^{\circ}=\tan ^{-1} \mathrm{~b}^{*} / \mathrm{a}^{*}$. As leituras foram efetuadas em quatro lados do fruto; diâmetro médio de frutos, medido diretamente com auxílio de um paquímetro digital colocado em posição perpendicular ao eixo do fruto na região equatorial, sendo realizadas duas medidas por fruto $(\mathrm{mm})$ e utilizada a média dessas medidas; produtividade (ton $\mathrm{ha}^{-1}$ ), considerando uma densidade de 1.333 plantas por hectare. Nos dois anos, a colheita dos frutos foi fracionada em três etapas (início, plena e fim de colheita), a produtividade foi obtida nas três colheitas e as demais variáveis foram avaliadas na segunda colheita, sendo esta a mais representativa.

O delineamento experimental foi em blocos casualizados, com três repetições, sendo utilizado um esquema fatorial em parcelas subdivididas, sendo considerado na parcela o fator época de poda (três) e na subparcela os genótipos (três). A unidade experimental foi constituída por cinco plantas, sendo as três centrais as úteis. Os dados foram submetidos à análise de variância pelo teste $\mathrm{F}$ e, quando o efeito de tratamento foi significativo, realizou-se teste de comparação de médias (Tukey) em nível de 5\% de probabilidade de erro.

\section{RESULTADOS E DISCUSSÃO}

A cultivar 'BRS Kampai' se destacou nos dois anos de avaliação na variável firmeza de polpa. Em 2009, Cascata 805 também obteve bons resultados não diferindo estatisticamente da BRS Kampai (Tabela 1). Os resultados de firmeza de polpa encontrados neste trabalho para a BRS Kampai foram superiores aos descritos por RASEIRA et al. (2010). Este comportamento pode ser explicado pelo fato de este genótipo ter apresentado as menores médias para a variável diâmetro de fruto (Tabela 2),

Tabela 1 - Firmeza de polpa (FP) (Kgf), pH, sólidos solúveis (SS) ( $\left.{ }^{b} b r i x\right)$, acidez titulável (AT) (\% de ácido cítrico), relação SS/AT e coloração ( ${ }^{\circ}$ hue) de pêssegos submetidos a diferentes épocas de poda. Embrapa Clima Temperado, Pelotas, RS, 2012.

\begin{tabular}{|c|c|c|c|c|c|c|}
\hline Genótipos & FP(Kgf) & $\mathrm{pH}$ & SS ( ${ }^{\circ}$ brix) & AT (\%ac.cít.) & SS/AT & ${ }^{\circ} h_{u e}{ }^{1}$ \\
\hline \multicolumn{7}{|c|}{ 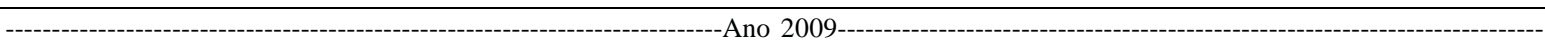 } \\
\hline BRS Kampai & $4,70 a^{*}$ & $4,55 \mathrm{~b}$ & $12,26 \mathrm{a}$ & 0,43 a & $28,36 \mathrm{~b}$ & $55,41 \mathrm{~b}$ \\
\hline BRS Rubimel & $3,39 \mathrm{~b}$ & $4,79 \mathrm{a}$ & $10,95 \mathrm{~b}$ & $0,34 \mathrm{~b}$ & $30,99 \mathrm{a}$ & $57,05 \mathrm{~b}$ \\
\hline Cascata 805 & $4,43 \mathrm{a}$ & $4,71 \mathrm{a} b$ & $11,36 \mathrm{~b}$ & $0,35 \mathrm{~b}$ & $32,80 \mathrm{a}$ & $68,77 \mathrm{a}$ \\
\hline & & & ---Época de & - & & 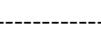 \\
\hline Inverno & $3,89 \mathrm{~b}$ & $4,73^{\text {ns }}$ & $11,34^{\mathrm{ns}}$ & $0,37^{\mathrm{ns}}$ & $30,88^{\mathrm{ns}}$ & 61,98 a \\
\hline Inverno e verão & 3,97 b & 4,67 & 11,55 & 0,37 & 30,94 & 62,45 a \\
\hline Verão & $4,66 \mathrm{a}$ & 4,65 & 11,68 & 0,38 & 30,32 & $56,80 \mathrm{~b}$ \\
\hline CV (\%) & 13,35 & 5,87 & 7,81 & 10,52 & 11,18 & 9,05 \\
\hline Genótipos & ------- & ------. & ----Ano 201 & - & - & - \\
\hline BRS Kampai & 5,18 a & $4,33 \mathrm{a}$ & 11,57 a & 0,39 a & $29,75 \mathrm{~b}$ & $57,40^{\text {ns }}$ \\
\hline BRS Rubimel & $4,71 \mathrm{~b}$ & $4,34 \mathrm{a}$ & $10,64 \mathrm{~b}$ & $0,30 \mathrm{~b}$ & $34,76 \mathrm{a}$ & 65,96 \\
\hline Cascata 805 & $4,54 \mathrm{~b}$ & 3,99 b & $10,80 \mathrm{~b}$ & $0,30 \mathrm{~b}$ & 36,14 a & 67,23 \\
\hline Inverno & $4,82^{\mathrm{ns}}$ & $4,25^{\mathrm{ns}}$ & $\begin{array}{l}\text {--Época de } \\
11,00^{\mathrm{ns}}\end{array}$ & $0,39^{\text {ns }}$ & $32,85^{\text {ns }}$ & 65,50 ns \\
\hline Inverno e verão & 4,82 & 4,21 & 11,11 & 0,32 & 34,53 & 67,50 \\
\hline Verão & 4,81 & 4,20 & 10,91 & 0,33 & 33,26 & 57,56 \\
\hline CV (\%) & 8,51 & 4,30 & 5,48 & 10,6 & 11,98 & 29,15 \\
\hline
\end{tabular}

*Médias seguidas de letras minúsculas distintas na mesma coluna diferem entre si, pelo teste de Tukey em nível de 5\% de probabilidade de erro. ${ }^{\text {ns }}$ não significativo; Ângulo hue ${ }^{\circ}\left(0^{\circ}=\right.$ vermelho, $90^{\circ}=$ amarelo, $180^{\circ}=$ verde, $360^{\circ}=$ azul $)$. 
concordando, assim, com o descrito por TREVISAN et al. (2006), quando verificaram que frutos de pessegueiro com menor diâmetro apresentaram maior firmeza de polpa.

O fator época de poda influenciou na firmeza de polpa dos frutos colhidos. Em 2009, verificou-se que as plantas submetidas à poda de verão apresentaram frutos com maior firmeza (4,66Kgf) (Tabela 1), diferindo dos resultados obtidos nas demais épocas de poda, possivelmente pelo fato de este tratamento ter proporcionado frutos de menor diâmetro (Tabela 2). Segundo SAMS (1999), frutos menores, em geral, apresentam maior firmeza da polpa por terem maior percentual do seu volume ocupado com materiais da parede celular, o que lhes proporciona maior densidade e resistência à penetração do êmbolo do penetrômetro.

Os frutos de BRS Rubimel apresentaram maiores médias de $\mathrm{pH}$, porém não diferiram estatisticamente de Cascata 805 no primeiro ano e de BRS Kampai no segundo (Tabela 1). A variação do pH também foi observada por RAMOS \& LEONEL (2008), avaliando características físico-químicas em diferentes genótipos de pêssegos e nectarinas no município de Botucatu-SP. Tanto no ano de 2009 como no de 2010, não houve variação significativa para $\mathrm{pH}$ referente ao fator época de poda (Tabela 1), indicando que este parâmetro sofre maior influência das características intrínsecas aos genótipos.

As diferentes épocas de poda não proporcionaram variação significativa nos SS, assim como, para AT (Tabela 1), concordando com ZANINI (2006), que, testando diferentes tipos de poda em pessegueiro Granada, também não obteve efeito dos tratamentos para estas variáveis. Dentre os genótipos, BRS Kampai apresentou o maior teor de SS nos dois anos avaliados, (12,26 e 11,57ºbrix, respectivamente), resultado similar ao descrito por RASEIRA et al. (2010), quando descreve que esta cultivar apresenta índices de SS entre 11 e $12^{\circ}$ brix. Variações entre genótipos também foram verificadas por LEONEL et al. (2011) em Botucatu/SP, quando estudaram a qualidade de diferentes genótipos de pessegueiro. Os genótipos estudados apresentaram índices de SS superiores, no primeiro ano de avaliação (Tabela 1), e provavelmente tenha como explicação as diferenças climáticas entre os dois anos de estudo. TORALLES et al. (2008) destacaram uma correlação significativa

Tabela 2 - Produtividade (ton.ha ${ }^{-1}$ ) e diâmetro médio de frutos (mm) de pessegueiros submetidos a diferentes épocas de poda. Embrapa Clima Temperado, Pelotas, RS, 2012.

\begin{tabular}{|c|c|c|c|}
\hline Genótipos & Inverno & Inverno e verão & Verão \\
\hline & \multicolumn{3}{|c|}{ 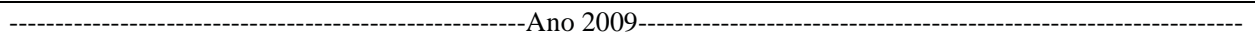 } \\
\hline & \multicolumn{3}{|c|}{ 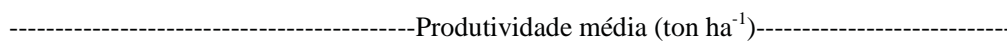 } \\
\hline BRS Kampai & $16,08 \mathrm{aB}$ & $14,59 \mathrm{bB}$ & $18,45 \mathrm{bA}$ \\
\hline BRS Rubimel & $16,31 \mathrm{aB}$ & $17,95 \mathrm{aB}$ & 29,62 aA \\
\hline Cascata 805 & $16,92 \mathrm{aB}$ & $16,20 \mathrm{abB}$ & $29,72 \mathrm{aA}$ \\
\hline \multirow[t]{2}{*}{ CV (\%) } & \multicolumn{3}{|c|}{9,41} \\
\hline & ----------- & etro médio de fru & '------------ \\
\hline BRS Kampai & $61,20 \mathrm{bA}$ & 61,37 bA & $51,22 \mathrm{bB}$ \\
\hline BRS Rubimel & $65,53 \mathrm{aB}$ & $67,85 \mathrm{aA}$ & $57,06 \mathrm{aC}$ \\
\hline Cascata 805 & $62,59 \mathrm{bA}$ & $63,00 \mathrm{bA}$ & $55,77 \mathrm{aB}$ \\
\hline CV (\%) & 3,03 & & \\
\hline \multirow[t]{2}{*}{ Genótipos } & \multirow{2}{*}{\multicolumn{3}{|c|}{ 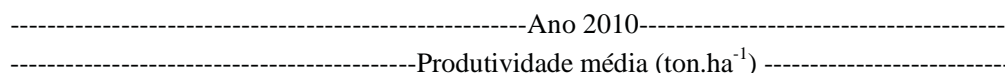 }} \\
\hline & & & - \\
\hline BRS Kampai & $17,13 \mathrm{abB}$ & $19,43 \mathrm{aA}$ & $19,68 \mathrm{aA}$ \\
\hline BRS Rubimel & 16,55 bB & $18,68 \mathrm{aA}$ & 17,25 bAB \\
\hline Cascata 805 & $18,49 \mathrm{aB}$ & 15,38 bC & $21,34 \mathrm{aA}$ \\
\hline \multirow[t]{2}{*}{ C.V. (\%) } & \multicolumn{3}{|c|}{8,85} \\
\hline & - & etro médio de fru & - \\
\hline BRS Kampai & & 55,16 с & \\
\hline BRS Rubimel & & 60,12 a & \\
\hline Cascata 805 & & 58,76 b & \\
\hline CV (\%) & & 3,12 & \\
\hline
\end{tabular}

*Médias seguidas por letras minúsculas distintas, na mesma coluna, e médias seguidas por letras maiúsculas distintas, na mesma linha, diferem entre si pelo teste de Tukey em nível de 5\% de probabilidade de erro. 
dos SS com a temperatura (máxima e mínima) como principal causa climática para o aumento do teor de açúcares em pêssegos.

Os frutos de BRS Kampai apresentaram maior AT nos dois anos de avaliação (0,43 e 0,39\% de ácido cítrico, respectivamente), diferindo dos demais genótipos (Tabela 1). A variação de acidez entre os genótipos concorda com o verificado por TORALLES et al. (2008), tanto em cultivares precoces como intermediárias. GIRARDI \& ROMBALDI (2003) destacaram que a acidez, para uma mesma cultivar, é influenciada por vários fatores, entre eles, as condições climáticas, o estádio de maturação e a localização do fruto na planta.

A relação entre SS e AT é uma das melhores formas de avaliação do sabor de uma fruta (CHITARRA \& CHITARRA, 2005). Para esta relação, os maiores valores foram encontrados nos frutos de Cascata 805, nos dois anos de avaliação, sendo eles 32,80 e 36,14, respectivamente, não diferindo estatisticamente, em ambos os anos, dos frutos de BRS Rubimel (Tabela 1). Segundo MAYER et al. (2008), os maiores valores da relação SS/AT demonstram a melhor palatabilidade do fruto para o consumo in natura. Ainda na tabela 1, verifica-se que os menores valores foram encontrados nos frutos de BRS Kampai, valores estes influenciados por sua acidez elevada. Já o fator época de poda manteve seu comportamento e, portanto, não influenciando significativamente a relação SS/AT, aspecto considerado importante, pois indica ser possível a realização de podas em diferentes épocas do ano sem comprometer a qualidade da fruta.

Segundo LI et al. (2002), a coloração da epiderme dos frutos é o principal parâmetro de qualidade atribuído pelo consumidor, principalmente no que se refere à coloração vermelha. A variável referente à cor representada pelo ângulo hue $\left({ }^{\circ} \mathrm{h}\right)$ apresentou diferenças estatísticas apenas entre os seus níveis, sendo os frutos de BRS Kampai e BRS Rubimel os que apresentaram maior coloração vermelha da epiderme, apresentando, assim, menores ângulos $\left(55,41^{\circ}\right.$ e $57,05^{\circ}$, respectivamente) no primeiro ano de avaliação (Tabela 1). Estes resultados comprovam a predominância do vermelho intenso, característica importante destes genótipos (SCARANARI et al., 2009). As plantas que receberam a poda apenas no período de verão produziram frutos com maior intensidade de coloração vermelha no primeiro ano de avaliação, apresentando o menor ângulo $\left(56,80^{\circ}\right)$. No segundo ano, não houve efeito significativo dos tratamentos para esta variável. Os resultados do primeiro ano concordam com os obtidos por RODRIGUES et al. (2009), em Piracicaba-SP, quando, testando variações na poda em Flordaprice, obtiveram maior coloração vermelha em frutos de plantas com poda de verão, poda esta semelhante à testada no presente estudo. O comportamento da coloração do fruto em relação à época de poda, provavelmente, tenha sido reflexo do crescimento vegetativo das plantas que receberam poda apenas no verão, sendo que estas não fecharam o dossel, permitindo assim uma maior penetração da luz no interior da copa (dados não quantificados). CHITARRA \& CHITARRA (2005) relatam que a exposição à luz solar pode induzir o desenvolvimento de cor mais rapidamente em alguns frutos que em outros, na mesma árvore, embora eles possam ter a mesma época de formação.

Para a variável diâmetro médio de frutos, foi evidenciada interação entre os fatores estudados apenas no primeiro ano de avaliação, sendo que os frutos de BRS Rubimel apresentaram a maior média, independente da época de poda no primeiro ano de avaliação (Tabela 2), mantendo o maior calibre no segundo ano, comprovando assim uma das suas principais características que é a de produzir frutos de calibre elevado (SCARANARI et al., 2009). No primeiro ano, as maiores médias foram registradas nas plantas que receberam poda de inverno mais poda de verão, sendo que este aumento de tamanho pode estar relacionado ao incremento da área foliar proporcionado por este tratamento. Conforme DEMIRTAS et al. (2010), plantas de damasco submetidas à poda de verão e inverno apresentam maior área foliar, quando comparadas com plantas diferentemente podadas.

A maior produtividade foi registrada nas plantas de Cascata 805 que receberam poda apenas no período de verão (Tabela 2), não diferindo de BRS Rubimel, no ano 2009, e BRS Kampai, no ano 2010. Cabe salientar que as plantas que receberam apenas a poda no período de inverno apresentaram uniformidade de produção nos dois anos. Este comportamento provavelmente foi devido ao equilíbrio entre crescimento vegetativo e reprodutivo.

RASEIRA et al. (2010) descrevem BRS Kampai como um genótipo menos produtivo, quando comparado com BRS Rubimel, fato este não confirmado com o presente estudo, pois BRS Kampai 
apresentou produção superior no segundo ano de avaliação nas plantas que receberam poda apenas no verão (Tabela 2). Segundo BARBOSA et al. (2000), em cultivo de plantas perenes, como o pessegueiro, pequenas diferenças produtivas verificadas de um ano para outro podem ser consideradas normais, já diferenças maiores podem afetar a produtividade, conforme observado no presente trabalho com plantas da BRS Rubimel, que receberam poda apenas no verão.

\section{CONCLUSÃO}

Nas condições experimentais adotadas, foi possível concluir que as características físicoquímicas de $\mathrm{pH}$, SS, AT e SS/AT não são alteradas com as variações de época de poda estudadas. A poda apenas de verão proporciona maior produtividade no primeiro ano de aplicação para todos os genótipos testados. A seleção Cascata 805 apresenta maior produtividade, quando manejada apenas com a poda de verão.

\section{AGRADECIMENTOS}

À Coordenação de Aperfeiçoamento de Pessoal de Nível Superior (Capes), pela concessão de bolsa, e à Empresa Brasileira de Pesquisa Agropecuária (EMBRAPA), pelo apoio logístico.

\section{REFERÊNCIAS}

ARAUJO, J.P.C. et al. Influência da poda de renovação e controle da ferrugem nas reservas de carboidratos e produção de pessegueiro precoce. Revista Brasileira de Fruticultura, v.30, n.2, p.331-335, 2008. Disponível em: <http://www.scielo.br/scielo. php?script=sci_arttext\&pid=S0100-29452008000200011\&lng= pt\&nrm=iso\&tlng=pt>. Acesso em: 11 out. 2012. doi: 10.1590/ S0100-29452008000200011.

BARBOSA, W. et al. O pessegueiro em pomar compacto: X. Comportamento de cultivares e seleções sob poda de encurtamento dos ramos pós-colheita. Bragantia, v.59, n.2, p.197-203, 2000. Disponível em: <http://www.scielo.br/pdf/brag/v59n2/ a11v59n2.pdf $>$.. Acesso em: 16 abr. 2012. doi: 10.1590/S000687052000000200011.

BOUND, S.A.; SUMMERS, C.R. The effect of pruning level and timing on fruit quality in red 'Fuji' apple. Acta Horticulturae, v.557 p.295-302, 2001. Disponível em: <http://www.actahort.org/ books/557/557_38.htm>. Acesso em: 14 out. 2013.

CHITARRA, M.I.F.; CHITARRA, A.B. Pós-colheita de frutas e hortaliças: fisiologia e manejo. 2.ed. Lavras: UFLA, 2005. 785p.

DEMIRTAS, M.N. et al. The effects of different pruning treatments on the growth, fruit quality and yield of 'Hacihaliloglu' apricot. Acta Scientiarum Polonorum, v.9, n.4, p.183-192, 2010. Disponível em: <http://www.acta.media.pl/pl/full/7/2010/0000702 01000009000040018300192.pdf> . Acesso em 16 abr. 2012.
EMBRAPA. Sistema brasileiro de classificação de solos. 2.ed. Rio de Janeiro: Embrapa Solos, 2006. 306p.

FACHINELLO, J.C. et al. Normas técnicas e documentos de acompanhamento da produção integrada de pêssego. Pelotas: Universidade Federal de Pelotas, Faculdade de Agronomia Eliseu Maciel, 2003. 95p.

GIRARDI, C.; ROMBALDI, C.V. Desenvolvimento e maturação de pêssegos. In: PROTAS, J.F.do S.; MADAIL, J.C.M (Eds.). Sistema de produção de pêssego de mesa na Região da Serra Gaúcha. Sistema de Produção, 3. Bento Gonçalves: EMBRAPA Uva e Vinho, 2003. (Versão eletrônica). Disponível em: <http:// sistemasdeproducao.cnptia.embrapa.br/FontesHTML/Pessego/ PessegodeMesaRegiaoSerraGaucha/index.htm>. Acesso em: 14 out. 2013.

LEONEL, S. et al. Produção e qualidade dos frutos de pessegueiro e nectarineira em clima subtropical do estado de São Paulo. Revista Brasileira de Fruticultura, v.33, n.1, p.118-128, 2011. Disponível em: <http://www.scielo.br/pdf/rbf/2011nahead/ aop02611.pdf>. Acesso em: 10 jan. 2013. doi: 10.1590/S010029452011005000043.

LI, Z.H. et al. Stimulation of Fuji apple skin color by ethephon and phosphorus-calcium mixed compounds in relation to flavonoid synthesis. Scientia Horticulturae, v.94, n.1, p.193-199, 2002. Disponível em: <http://www.sciencedirect.com/science/article/pii/ S0304423801003636>. Acesso em: 14 out. 2013.

MADAIL, J.C.M.; RASEIRA, M. do C.B. Aspectos da produção e mercado do pêssego no Brasil. Pelotas: Embrapa Clima Temperado, 2008. 14p.

MAYER, N.A. et al. Qualidade pós-colheita de pêssegos de cultivares e seleções produzidos na microrregião de JaboticabalSP. Revista Brasileira de Fruticultura, v.30, n.3, p.616621, 2008. Disponível em: <http://www.scielo.br/pdf/rbf/ v30n3/09.pdf>. Acesso em: 11 jan. 2013. doi10.1590/S010029452008000300009.

RAMOS, D.P.; LEONEL, S. Características dos frutos de cultivares de pessegueiros e de nectarineira, com potencial de cultivo em Botucatu, SP. Bioscience Journal, v.24, p.10-18, 2008. Disponível em: <http://www.seer.ufu.br/index.php/biosciencejournal/article/ view/6774/4471>. Acesso em: 14 out. 2013.

RASEIRA, M. do C.B. et al. Pessegueiro: Cultivar 'BRS Kampai'. Revista Brasileira de Fruticultura, v.32, n.4, p.1275-1278, 2010. Disponível em: <http://www.scielo.br/pdf/rbf/v32n4/ aop13310.pdf>. Acesso em: 11 jan. 2013. doi: 10.1590/S010029452011005000009.

RODRIGUES, A. et al. Desenvolvimento do pessegueiro 'Flordaprince' sob duas intensidades de poda verde. Bragantia, v.68, n.3, p.673-679, 2009. Disponível em: <http://www.scielo. br/pdf/brag/v68n3/a14v68n3.pdf>. Acesso em: 11 jan. 2013. doi: 10.1590/S0006-87052009000300014.

SAMS, C.E. Preharvest factors affecting postharvest texture. Postharvest Biology and Technology, v.15, n.6, p.249-254, 1999. Disponível em: <http://www.sciencedirect.com/science/article/pii/ S0925521498000982>. Acesso em: 14 out. 2013.

SCARANARI, C. et al. Catálogo de cultivares de pêssego e nectarina. Pelotas, Embrapa Clima Temperado, 2009. 136p. 
TORALLES, R.P. et al. Características físicas e químicas de cultivares brasileiras de pêssegos em duas safras. Revista Brasileira de Agrociência, v.14, n.2, p.327-338, 2008. Disponível em: <http://www.ufpel.edu.br/faem/agrociencia/v14n2/artigo14. pdf>. Acesso em: 14 out. 2013.

TREVISAN, R. et al. Influência de práticas culturais na melhoria da qualidade de pêssegos. Revista Brasileira de Agrociência, v.12, n.4, p.491-494, 2006. Disponível em: <http://www.ufpel.tche.br/ faem/agrociencia/v12n4/artigo17.pdf>. Acesso em: 14 out. 2013.
ZANETTI, F.; BIASI, L.A. Introdução à fruteiras de caroço. In: MONTEIRO, L.B. et al. Fruteiras de caroço: uma visão ecológica. Curitiba: UFPR, 2004. p.01-04.

ZANINI, C.L.D. Tipos e épocas de poda do pessegueiro 'Granada' em pomar conduzido em produção integrada. 2006. 70f. Dissertação (Mestrado em Fitotecnia) - Programa de Pósgraduação em Fitotecnia, Área de concentração em Horticultura, Universidade Federal do Rio Grande do Sul, RS. 